\title{
Usability testing on intelligent mobile web pre-fetching of cloud storage scheme
}

\author{
Nur Syahela Hussien a,b,1, , Sarina Sulaiman a,b,2, *, Siti Mariyam Shamsuddin ${ }^{\mathrm{a}, \mathrm{b}, 3,}$ \\ ${ }^{a}$ UTM Big Data Centre, Ibnu Sina Institute for Scientific and Industrial Research \\ ${ }^{b}$ Faculty of Computing, Universiti Teknologi Malaysia, 81310 Skudai, Johor, Malaysia \\ Inursyahela_90@yahoo.com; ${ }^{2}$ sarina@utm.my*;3mariyam@utm.my \\ * corresponding author
}

ARTICLE INFO

ABSTRACT

Article history:

Received November 20, 2017

Revised November 30, 2017

Accepted November 30, 2017

Keywords:

Usability testing

Mobile cloud storage

Cloud storage services

Intelligent pre-fetching
Mobile device and Cloud Storage (CS) represent the trends of technology usage of the last few years. However, the difficulty in managing the data when there are too many simultaneous uses of cloud storage services at the same time that can cause latency or delayed time. This paper evaluates mobile cloud storage services using usability testing, which is intended to access by multiple of Cloud Storage Services (CSS) with the proposed Intelligent Mobile Web Pre-fetching of Cloud Storage Scheme (MOBICS). The results show most of the respondents with $95.65 \%$ agree that MOBICS system is useful and has enhanced the speed in accessing and storing data by Mobile Cloud Storage (MCS). Besides, MOBICS reduces time of interaction up to $19.28 \%$ for the local pre-fetching and $18.80 \%$ for the intelligent pre-fetching.

Copyright $\odot 2017$ International Journal of Advances in Intelligent Informatics. All rights reserved.

\section{Introduction}

This research has proposed and designed the development of scheme for Mobile Intelligent Cloud Storage (MOBICS) to implement the Machine Learning (ML) technique. The aim of this proposed scheme is to enable multiple Cloud Storage Services (CSS) being access by mobile users anytime and anywhere. Besides, this research enhances the loading speed of MOBICS, which reduces the total loading time to access the user data. The enhancement of loading speed is proven by using Advanced Keystroke Level Model (KLM) model. To evaluate the usability testing on the proposed scheme of MOBICS, questionnaire is distributed, in which the result may be biased if it is not properly handled. Usability testing is common with huge numbers issues identifying with how great an exploration reflects genuine framework usage. For instance, how accurately the task situation mirrors a real context of utilization and how those investigate participants represent the target client group [1]-[2]. Usability comprises the aspects effectiveness and efficiency. Normally during lab experiment bias from respondents may occur. The researcher must try to be extra cautious when they analyse the results. When the users know they are being observe, they may be bias while doing the experiment. This situation is known as Hawthorne effect that it is an experimenter outcome whereby participants, in any human-centred research, might show regularly large amounts of execution basically in light of they would mindful that they need aid being concentrated on [2]-[3].

The first investigations that provided for ascent of the Hawthorne effect were embraced toward Western electric phone manufacturing plant at Hawthorne, close to Chicago, the middle of 1924 What's more 1933 [3]. Responsiveness to constantly watched alternately hosting conduct evaluated causes convictions over specialist desires. Conventionality and social allure considerations, subsequently guide conduct technique to progress in line with these desires [3]. Chiesa and Hobbs [4] pointed out that there are distinctive implications provided for of the purported Hawthorne effect, and additionally a large number proposed components generating those effect. Altogether likelihood, the greater part as a relatable point utilization of those Hawthorne effect be similarly as post hoc translation for unforeseen look into findings, especially the place they would disappointing. Statistical test was applied to test the heterogeneity as a step to be aware of Hawthorne effect. The statistical test 
is including the Chi-square statistic $\left(\mathrm{Chi}^{2}\right)$ and $\mathrm{I}^{2}$ statistic. Pocket caching scheme is exhibited Similarly as a pre-fetching reserve system to recognize those information should be stacked done a portable hub taking an interest on mobile cloud computing environment [5]. Client collaboration might make influenced toward system issues in a few focuses for enthusiasm. This circumstance need persuaded pocket caching proposition. Pocket caching recommended to decrease information accessibility issues in focuses for interest, and in addition plans a multi-objective optimisation system with incorporate aspects about Mobile Cloud Computing (MCC) nature's domain and some requisition practices.

Anu and Anu Priya[6] implemented and evaluated an initiative data pre-fetching scheme on the capacity servers for dispersed document systems, which might be utilized likewise backend capacity framework clinched alongside a boisterous nature's domain that might have certain resource-limited customer machines. The pre-fetched information can be pushed to the relevant the pertinent customer machine from the capacity server. Moreover, Wang and Chen [7] utilized the Cloud Computing (CC) innovation to propose a new framework to enhance the quality of Really Simple Syndication (RSS) reading service for portable clients called Pre-Feed. The social relationship is more effective to predict the access likelihood. For RSS feeds, clients might subscribe to well-known natives and particular content publishers. Sharma and Dubey [8] provided a semantic-based pre-fetching scheme for the web browsers should succeed those restrictions of existing frameworks. The existing techniques are based on URL's of the web objects, client right. Utilization of area metaphysics with those semantics settles on this procedure simpler and powerful.

Nevertheless, there have been many studies carried out in pre-fetching schemes, focusing on its usage in reducing latency in different fields of study with different algorithms applied in their work. Many studies have used ML to solve such issues. Nevertheless, pre-fetching using ML is not widely used in MCC environment. Therefore, based on previous schemes this research proposes an intelligent mobile web pre-fetching scheme to improving the current CSS.

\section{Method}

Users can access their data file faster by using MOBICS because it predicts the data requested by future users using pre-fetching technique. Besides, MOBICS provides a recommendation to store the data on CSS based on their availability and most frequent access. Fig 1 shows the scheme of the proposed MOBICS which comprises of two schemes. First, the scheme is to analyse local and intelligent mobile web pre-fetching on cloud storage services environment. For the second time and the next use, the MOBICS fetches the data from proxy cache, pre-fetching into four kinds of prefetching including the public most visited cloud storage that list the most top ranking cloud storage user most visited, and then user can directly access the data.

Second, pre-fetch based on the ranking cloud storage, MOBICS will list the most recommendation of cloud storage for user to store their data on which CS is still available based on the bigger size of CS. For the private most visited CS is similar like ranking CS but has other feature by list the highest hit of CS data. The final is pre-fetching based on J48 decision tree rules, which the rules are from the best ML classifier. ML predictor is designed to determine the best ML technique by producing prediction with highest accuracy. The scheme is designed and begins with extraction of the data from log datasets including the IrCache, UTM blog and Proxy CS. The datasets need to be pre-processed before they are analysed using ML techniques. In this scheme, the effective ML techniques on prediction are determined. This research proved that, J48 decision tree provided highest accuracy and effectiveness. Therefore, J48 is selected to be used to generated decision tree rules.

The experiment is conducted to get the information before and after the respondents use the proposed MOBICS scheme. Each respondent answered the questionnaire that consisted of twelve questions before and six questions after they went through the proposed MOBICS scheme. The questionnaire is user's opinions and attitude towards the usability of application are collected through question items based on Simple Usability Scale (SUS) that provides a global perspective of subjective assessments of usability [9]-[10]. Usability is actually a measurement of the usefulness a system from the user's perspective. SUS allocates designer to evaluate a wide range of products and services, containing hardware, software, portable devices, websites and applications. SUS is the mainly accepted identical usability questionnaire. The questionnaire designed to determine 
users' perceived usability of a product or system and takes in capability of the item alternately framework constantly contemplated. The aims for this part are to recognize the respondents' profile and Internet use background in order to determine the top activities in MCS and to get the feedback from the implementation of a MOBICS system to the MCS users. The sixty-nine respondents tested this system. Mobile cloud storage was used as the case study to test the MOBICS system.

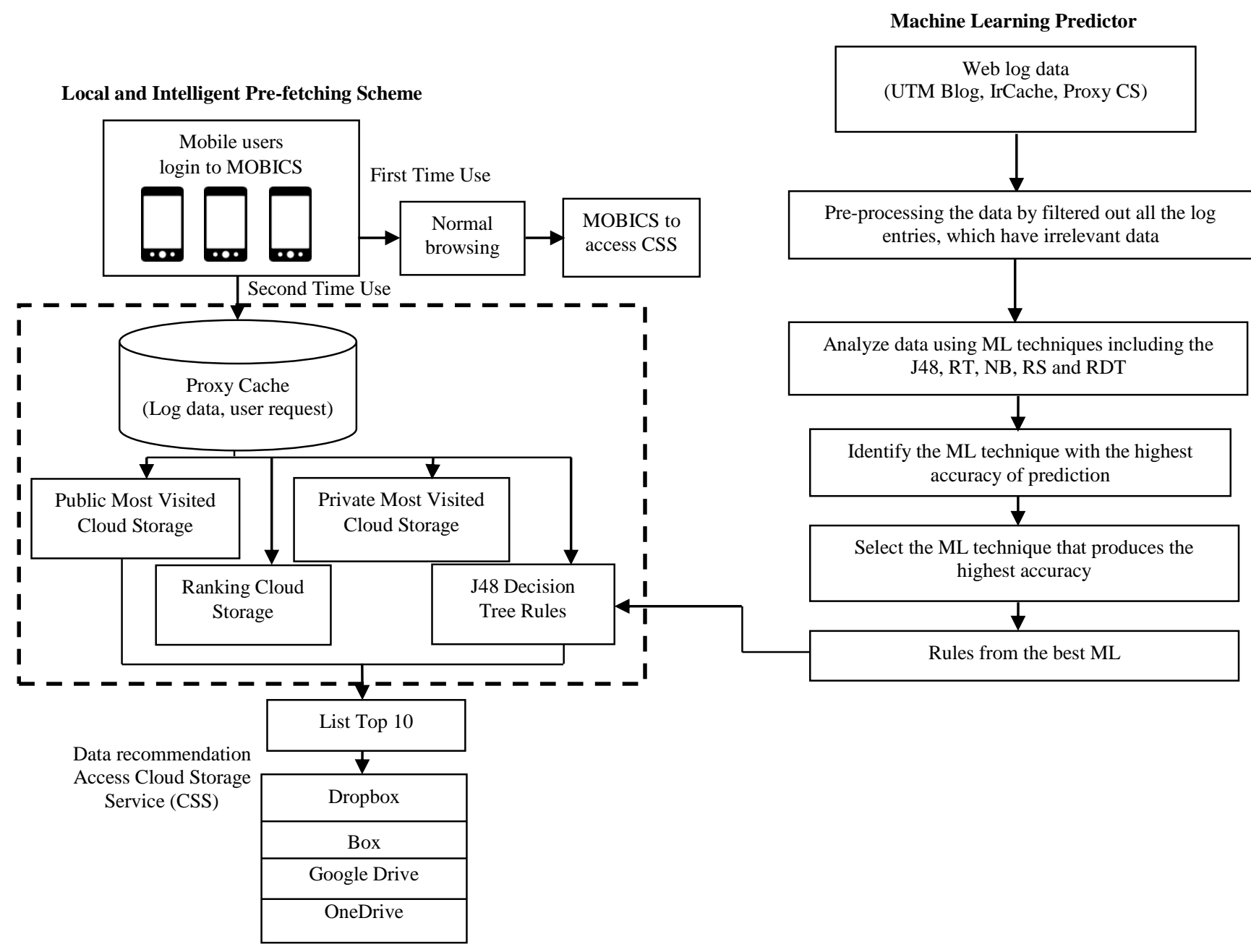

Fig. 1. Proposed Scheme of MOBICS

\section{Results and Discussion}

The results for questionnaire divided into three categories; the background of respondents, the ranking activities in mobile cloud storage and feedback from users on the implementation of mobile intelligent web pre-fetching for mobile cloud storage.

\section{A. The Background of Respondents}

The aim of this part is to recognise the background profile of all respondents based on the questionnaire. In addition, Cochran's Q Test was employed to see the significance of these results with the implementation of MOBICS with awareness of Hawthorne effect.

\section{1) Background of Profile User}

Based on the questionnaire, background information like gender, race, age, education level and current status of the respondents was collected. From the survey, about $39.13 \%$ were male and $60.87 \%$ female. Besides, about $18.84 \%$ were aged between 18 and 22, $71.01 \%$ were around 23 to 28 years old and $10.14 \%$ aged above 28 years. Based on the results, questionnaire is suitable for this evaluation because young adults are active in using the Internet and CS system. Moreover, the respondents of the diploma or bachelor degree were about $76.81 \%$, and $28.99 \%$ were master or $\mathrm{PhD}$ students, and the rest only $8.70 \%$. Table 1 summarizes the respondents' profile. In addition, $62.32 \%$ respondents were 
students and $37.68 \%$ were employed. Based on these results, this research could find the activity, behaviour from many kinds of users as shown in Table 1.

Table 1. Profile of respondents

\begin{tabular}{ccc}
\hline Variable & Description & $\begin{array}{c}\text { Number of } \\
\text { respondents }\end{array}$ \\
\hline \multirow{2}{*}{ Gender } & Male & 27 \\
& Female & 42 \\
\hline \multirow{2}{*}{ Race } & Malay & 62 \\
& Chinese & 7 \\
\hline \multirow{2}{*}{ Age } & $18-22$ & 13 \\
& $23-28$ & 49 \\
\multirow{2}{*}{ Education Level } & Above 28 & 7 \\
\hline \multirow{2}{*}{ Current Status } & Diploma/ Bachelor & 53 \\
& Master / PhD & 20 \\
& Others & 6 \\
\hline & Student & 43 \\
& Employed & 26 \\
\hline
\end{tabular}

\section{2) Internet Experience}

The results show that $85.51 \%$ respondents accessed the Internet every day. Moderately about $10.14 \%$ accessed the Internet less than five times in a week. Only $4.35 \%$ respondents browsed Internet five times a week. No one accessed the internet less than 1 hour per day based on the questionnaire. About $23.19 \%$ spent one to three hours per day on browsing while $40.58 \%$ spent about four to five hours per day, and $36.23 \%$ used more than five hours per day. The results were clearly showed that respondents had a high rating on using the Internet as shown in Tables 2 and 3 . The reason is most of them spent a lot of time to browse the Internet everyday. Besides, from the questionnaire, it found that most users had the CS.

Table 2. Frequency of the Internet Usage

\begin{tabular}{cccc}
\hline $\begin{array}{c}\text { Internet Usage } \\
\text { (a week) }\end{array}$ & Everyday & Five times & $\begin{array}{c}\text { Less than five } \\
\text { times }\end{array}$ \\
\hline $\begin{array}{c}\text { Number of people } \\
\text { Percentage }\end{array}$ & 59 & 3 & 7 \\
\hline
\end{tabular}

Table 3. Time Spent on the Internet Browsing

\begin{tabular}{ccc}
\hline $\begin{array}{c}\text { Time for Internet } \\
\text { Browsing }\end{array}$ & Number of people & Percentage (\%) \\
\hline Less than 1 hour/day & 0 & 0 \\
1-3 hours/day & 16 & 23.19 \\
4-5 hours/day & 28 & 40.58 \\
More than 5 hours/day & 25 & 36.23 \\
\hline
\end{tabular}

\section{B. The Ranking Activities in Mobile Cloud Storage}

This part is to recognize the ranking activities in Mobile Cloud Storage. Additionally, to identify the significance of these results, the effect of the respondents' background for MOBICS, Cochran's Q Test was specifically applied to see the trend.

1) Background on Type of CS access

This work tested on Dropbox, Google Drive, OneDrive and Box because most people used those CS as their storage services. It can be proven based on our survey by defining the type of CS they used often as Fig. 2. From the questionnaire, about 54 users were using the Dropbox, which is the highest usage of CS services. This result was followed by OneDrive with 41 users and only 3 users used Media Fire. The reason of having such result in this situation is because, todays Dropbox and OneDrive are the most popular CS services and Google Drive was also frequently used by users. 
Furthermore, those CS are in the list of top ten CS services[11]-[13]. Moreover, mostly one user has used multiple CS for storing their data. MOBICS has supported multiple CSS on one application. In addition, based on questionnaire result, about $80 \%$ of respondents used a CS by visiting the current data compared with just storing a new data. Hence, MOBICS is useful by having local and intelligent pre-fetching to speed up user's data access to most visited data files.

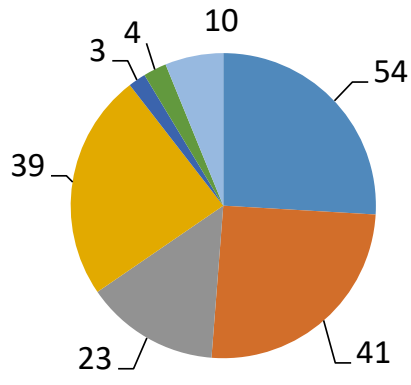

$$
\begin{aligned}
& \text { Dropbox } \\
& \text { Onedrive } \\
& \text { Box } \\
& \text { GoogleDrive } \\
& \text { Flickr } \\
& \text { SugarSync } \\
& \text { Media Fire }
\end{aligned}
$$

Fig. 2. Usage of cloud storage services

\section{2) Assessment of Mobile Cloud Storage}

The users were asked for their favourite Mobile Cloud Storage (MCS) before the users assessed and tried the proposed system. Based on Fig. 3, about 53 respondents (76.81\% users) liked using the Dropbox compared with others. Furthermore, users also liked using OneDrive and Google Drive. From the survey, most of the users used the CS to access their current data files.

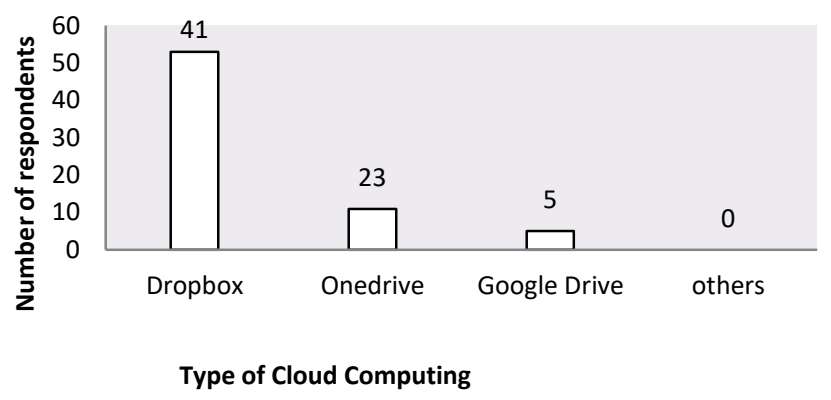

Fig. 3. The most favoured types of CS

\section{Feedback from users on the Implementation of Mobile Intelligent Web Pre-fetching for Mobile Cloud Storage}

This section describes the evaluation performance to get an implementation feedback on the local and intelligent pre-fetching on MOBICS system. Then, the result of this part of questionnaire is used to test the variables.

MOBICS system was requested by each user and browse through any Mobile Cloud Storage (MCS). MOBICS saved and calculated the hit number for each data object of CS. Then, from the most visited pages provided in the system, the users could view the history of hit based on the elements. Most visited page provided the users with their favourite and current information. Furthermore, MOBICS also saved the size of CS available and used, so MOBICS have recommended users to store at the available CS without checking the availability of each one. In addition, MOBICS provided list of result based on decision tree that provided data being requested in future by the users. The results prove that, commonly users had interests in viewing their files as files element had the highest hit compared with other elements.

On the last question of the questionnaire, users were asked about their experiences of using the MOBICS system while browsing through the features. About $40.58 \%$ agreed on the usability of the pre-fetching features while $44.93 \%$ strongly agreed that pre-fetching was useful to provide users navigate the multiple CS data as in Fig. 4.

Fig. 5 defines the evaluation result of MOBICS based on the users' experience while interacting with the system to browse through MCS. Some 30 and 27 users from 69 respondents strongly agreed 
and agreed respectively, that MOBICS sped up their browsing, and it was comparable to the traditional MCS application without MOBICS.

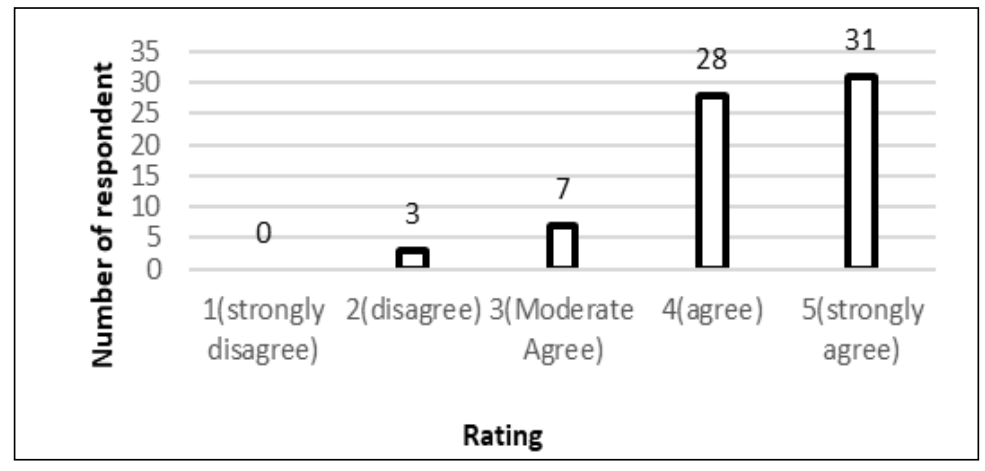

Fig. 4.Usability of MOBICS

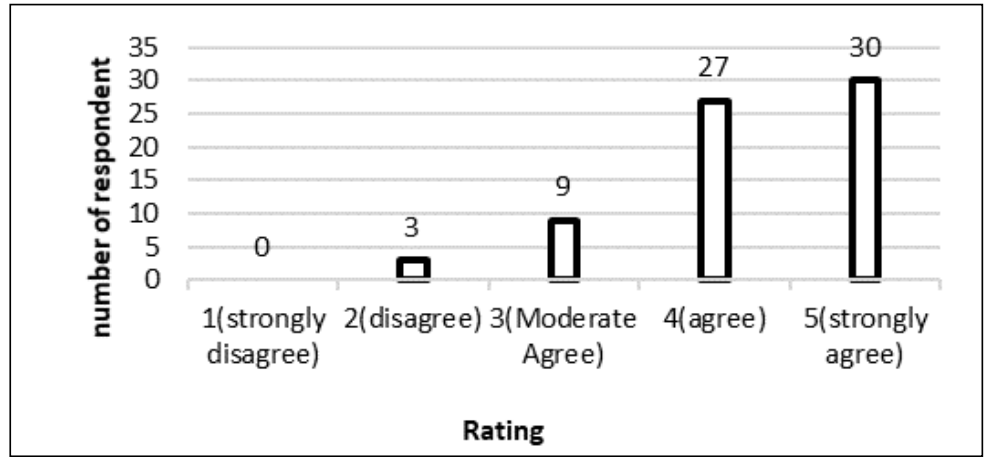

Fig. 5. Users' feedback on speed browsing the MOBICS system

The previous results presented the descriptive statistical feedback from the respondents of MOBICS system performance. Moreover, to identify the dependencies of these results for MOBICS, statistical test was also applied to test the heterogeneity as a step to be aware of Hawthorne effect. The statistical test, include the Chi-square statistic $\left(\mathrm{Chi}^{2}\right)$ and $\mathrm{I}^{2}$ statistic.

- $\mathrm{Chi}^{2}$ statistic. It is a test for heterogeneity. Heterogeneity is indicated by a Chi ${ }^{2}$ statistic greater than the $d f$ (degrees of freedom) and a small $\mathrm{P}$ value (for example: $\mathrm{P}<0.05$ )

- $\mathrm{I}^{2}$ statistic. $\mathrm{I}^{2}$ is a test used to measure heterogeneity and calculate the proportion of difference due to heterogeneity rather than possibility. The $\mathrm{I}^{2}$ value ranges from $0 \%$ to $100 \%$, with higher values indicating greater heterogeneity.

As it can be seen in Fig. 5, the ratings for MOBICS are 1 (strongly disagree), 2 (disagree), 3 (moderate), 4 (agree) and 5 (strongly agree). Nevertheless, ratings 1 and 2 were grouped as one (named as group 2), rating 3 as group 3 and ratings 4 and 5 as group 4 . Subsequently, the outcomes or variable labels, $k=3$ with test statistic are given in (1).

$$
\mathrm{Q}=\sum \frac{(\text { observed-expected })^{2}}{\text { expected }}
$$

Compute the chi square statistic $Q$ by carrying out the following steps:

1. On all observed number in the Table, deduct the corresponding expected number (observed expected).

2. Square the difference [ (observed - expected $\left.)^{2}\right]$.

3. Divide the squares obtained for every cell in the Table by the expected number for that cell

4. $\left[(\text { observed - expected })^{2} /\right.$ expected]

5. Total all the values for (observed - expected) $)^{2} /$ expected. This is the chi square statistic.

While, an Index, $\mathrm{I}^{2}$ given in equation (2), which does rely on upon the number of studies, the type of result information can be used to quantify those effect about heterogeneity and assess conflict. 


$$
I^{2}=\frac{Q-d f}{Q} \times 100 \%
$$

Where $\mathrm{Q}$ is the chi-squared statistic and df is its degrees of freedom [14]-[15]. This explains the percentage of the essentially estimates that it may be because of heterogeneity as opposed inspecting slip (chance). Thresholds to the elucidation from claiming $\mathrm{I}^{2}$ could make misleading, since the vitality about conflict relies once a few variables. The $\mathrm{I}^{2}$ represents the value of heterogeneity that may lead to risk of bias. A rough guide to understanding is as follows:

- Might not be important in range of $0 \%$ to $40 \%$;

- May represent moderate heterogeneity in range of $30 \%$ to $60 \%$;

- May represent the substantial heterogeneity in range of 50\% to $90 \%$;

- Considerable heterogeneity in range of $75 \%$ to $100 \%$.

A deficiency of the $\mathrm{Q}$ statistic is that it has poor control should identify valid heterogeneity around investigations when the meta-analysis incorporates a little amount of investigations and too much power to recognize unimportant variability with a high number of studies [3]. Thus, a no significant result for the $Q$ test with a little amount of studies can lead a reviewer to erroneously assume a fixedeffects model when there is true heterogeneity among the studies and vice versa. On the other hand, the $\mathrm{Q}$ statistic does not inform us of the degree for genuine inconsistency heterogeneity, just about its measurable hugeness.

In order to overcome the deficiencies of the Q, Higgins and Thompson [14] and Higgins, et al. [15] proposed three indices to assess heterogeneity in a meta-analysis: the $H^{2}, R^{2}$, and $I^{2}$ indices in their research. The preferences from claiming $\mathrm{I}^{2}$ index include incorporate simple interpretation, extensive variety for applications, simple to calculate and might normally be determined starting with distributed meta-analyses and can be straightforwardly compared the middle of meta-analyses for separate numbers from claiming investigations and different sorts for result information [16].

Table 4 shows the effects of heterogeneity in the respondents' profile background of the Hawthorne effect with binary outcome; whether or not it affects the ranking of MOBICS feedback. Part A from questionnaire was used to determine if the results of MOBICS were biased by the Hawthorne effect. The binary outcome as in Table 5 was used to identify the demographic and background of the Hawthorne effect on respondents. Based on the result, gender and race did not affect the results of the questionnaire because this questionnaire evaluated the system not the users. While age categories into three, which is majority is a student. Hence, they are normally known to use the system. Hence, they were less susceptible to the Hawthorne effect because users effectively got used to it. Same goes to the education level. The user effectively got used to it. It is proven by systematically testing both, the $\mathrm{Chi}^{2}$ statistic and $\mathrm{I}^{2}$ statistic. All the aspects on profile background show that the value of $\mathrm{P}>0.05$ means that gender, race, age and education level did not influence the ranking of MOBICS feedback. Moreover, the results of $\mathrm{I}^{2}$ were less than $40 \%$, which might not be important for ranking of MOBICS feedback. Based on Part A, it can be concluded that there was less Hawthorne effect occurred because the majority of result get effectively to use it and not for the reason was being observed.

Table 5 shows the binary result in determining the MCS usage background of the Hawthorne effects on respondents. Based on the result, the frequency of the internet usage and the time spent did not affect the ranking of MOBICS feedback because the statistics result was less than $40 \%$. However, it can be concluded that there might be less Hawthorne effect occurred. Hence, these results show proposed MOBICS reduced the Hawthorne Effect by reduce the bias's result occurred.

Table 4. The effect of heterogeneity in respondents' profile background on the Hawthorne Effect with binary outcomes

\begin{tabular}{ccccc}
\hline & $\mathrm{Q}$ & $d f$ & $\mathrm{P}$ & $\mathrm{I}^{2}(\%)$ \\
\hline Gender & 2.273 & 2 & 0.330 & 12.01 \\
Race & 2.948 & 2 & 0.078 & 32.15 \\
Age & 2.360 & 2 & 0.573 & 15.27 \\
Education Level & 2.925 & 2 & 0.368 & 31.62 \\
\hline
\end{tabular}


Table 5. The effect of heterogeneity in respondents' MCS usage background on the Hawthorne Effect with binary outcomes

\begin{tabular}{ccccc}
\hline & $\mathrm{Q}$ & $d f$ & $\mathrm{P}$ & $\mathrm{I}^{2}(\%)$ \\
\hline $\begin{array}{c}\text { Frequency of the } \\
\text { Internet Usage }\end{array}$ & 2.948 & 2 & 0.078 & 32.15 \\
Time Spend & 2.947 & 2 & 0.168 & 32.14 \\
\hline
\end{tabular}

The other experiment was proposed to evaluate the completion time of Dropbox application with or without using MOBICS system. The advanced KLM was used to compare the performance[17], [18].This model has also been discussed by other researchers[17], [19], [20].

To obtain results for this experiment, four Scenarios were applied in this experiment. There were some facts needed to be followed:

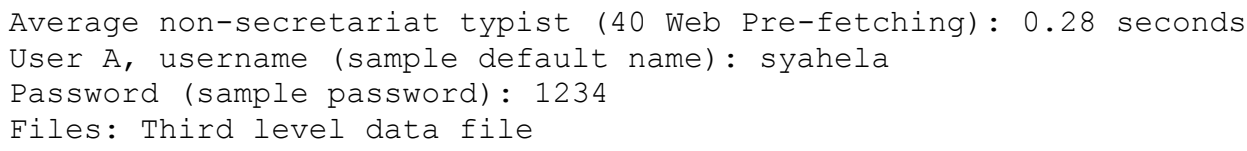

\section{1) First Scenario}

This Situation was used for a user who did not use Intelligent Mobile Web Pre-fetching at all. The user must open the web browser, then type the URL of Dropbox mobile (http://dropbox.com). A calculation of the time duration is provided in Table 6 .

Table $6.1^{\text {st }}$ scenario to get the total time

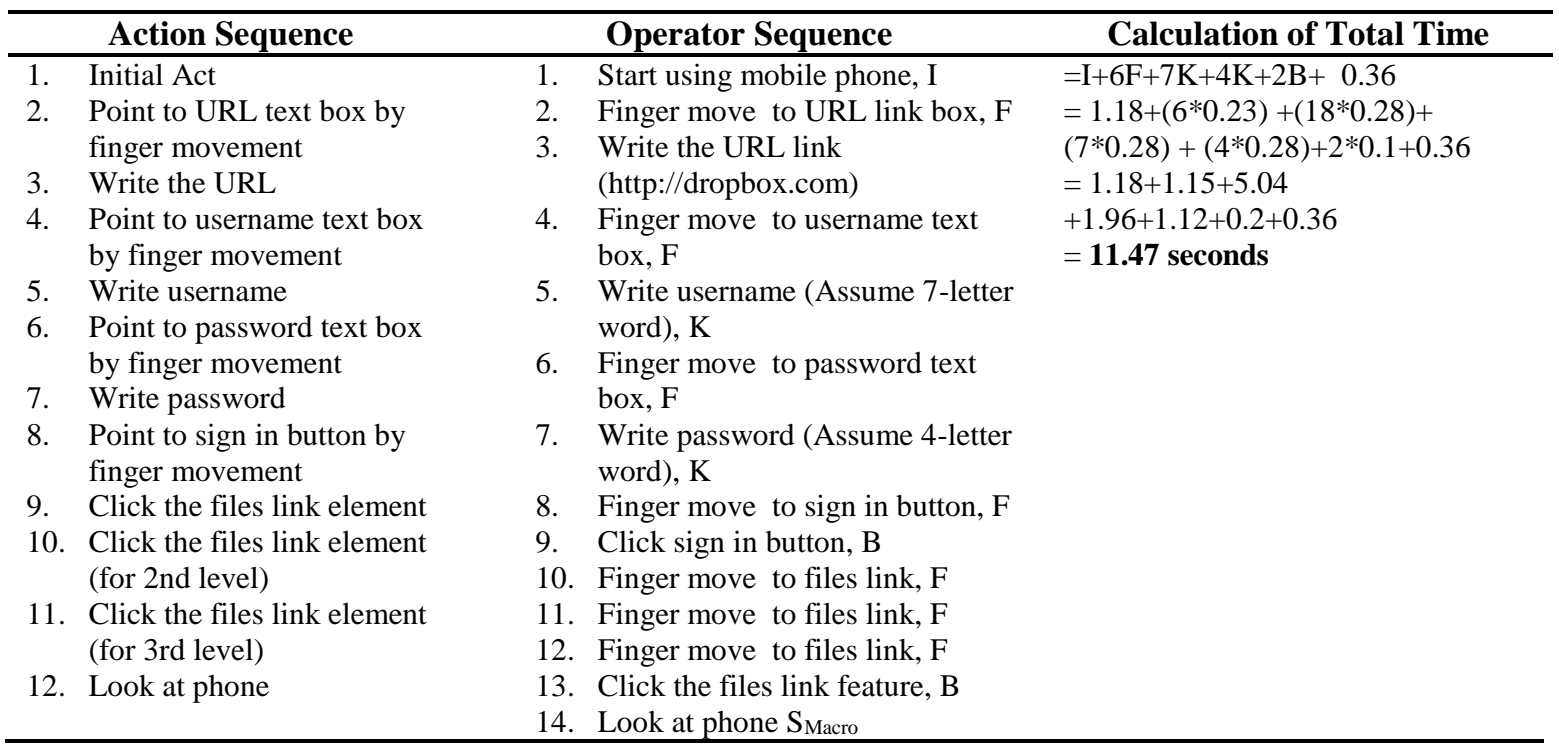

\section{2) Second Scenario}

A user logged in Dropbox Mobile without Intelligent Mobile Web Pre fetching system, and the home element display. Then, the user continued to browse on other elements. For instance, user A wanted to see the files. The user did not need to key-in the username and password. It is assumed that the user used the similar username and password. Hence, it saved the time to write username and password and also click the login button. As described in the third situation, the user did not need to insert Dropbox Mobile password again (Table 7). 
Table 7. $2^{\text {nd }}$ scenario to get the total time

\begin{tabular}{|c|c|c|c|}
\hline \multicolumn{2}{|r|}{ Action Sequence } & Operator Sequence & \multirow{2}{*}{$\begin{array}{r}\text { Calculation of Total Time } \\
\end{array}$} \\
\hline 1. & Initial Act & Start using mobile phone, I & \\
\hline 2. & $\begin{array}{l}\text { Point to username text box } \\
\text { by finger movement }\end{array}$ & $\begin{array}{l}\text { Finger move to username text } \\
\text { box, } \mathrm{F}\end{array}$ & 0.36 \\
\hline 3. & Write username & Write username (Assume 7-letter & $=1.18+(5 * 0.23)+(7 * 0.28)$ \\
\hline & Point to password text box & word), $\mathrm{K}$ & $+(4 * 0.28)+2 * 0.1+0.36$ \\
\hline & by finger movement & 4. Finger move to password text & $=1.18+0.92+1.96+1.12+0.2+0.36$ \\
\hline 5. & Write password & & $=6.2$ seconds \\
\hline 6. & $\begin{array}{l}\text { Point to login button by } \\
\text { finger movement }\end{array}$ & $\begin{array}{l}\text { 5. Write password (Assume 4-letter } \\
\text { word), K }\end{array}$ & \\
\hline 7. & Click the files link feature & Finger move to login button $\mathrm{F}$ & \\
\hline & Click the files link feature & 7. Click login button, $\mathrm{B}$ & \\
\hline & (for $2^{\text {nd }}$ level) & Finger move to files link, $\mathrm{F}$ & \\
\hline & Click the files link & 9. Finger move to files link, $\mathrm{F}$ & \\
\hline & element (for 3rd level) & 10. Finger move to files link, $\mathrm{F}$ & \\
\hline & Look at phone & 11. Click the files link feature, B & \\
\hline & & 12. Look at phone $S_{\text {Macro }}$ & \\
\hline
\end{tabular}

\section{3) Third Scenario}

The first time login a user should finish some of the steps as in the first situation. Although, for the second and the next logins, a user was allowed to directly access the files pages as it was assumed the files had the highest hit number by visiting the most visited page (Table 8).

Table 8. $3^{\text {rd }}$ scenario to get the total time

\begin{tabular}{|c|c|c|}
\hline Action Sequence & Operator Sequence & Calculation of Total Time \\
\hline Initial Act & Start using mobile phone, I & $=\mathrm{I}+4 \mathrm{~F}+7 \mathrm{~K}+4 \mathrm{~K}+\mathrm{B}+0.36$ \\
\hline $\begin{array}{l}\text { 2. Point to username text box by } \\
\text { finger movement }\end{array}$ & $\begin{array}{l}\text { 2. Finger move to username text } \\
\text { box, } \mathrm{F}\end{array}$ & $=1.18+(3 * 0.23)+(7 * 0.28)+$ \\
\hline 3. Write username & Write username (Assume 7-letter & $(4 * 0.28)+0.1+0.36$ \\
\hline Point to password text box by & word), $\mathrm{K}$ & \\
\hline $\begin{array}{l}\text { finger movement } \\
\text { 5. Write password }\end{array}$ & $\begin{array}{l}\text { 4. Finger move to password text } \\
\text { box, } \mathrm{F}\end{array}$ & $=1.18+0.69+1.96+1.12+0.1$ \\
\hline $\begin{array}{l}\text { 6. Point to login button by finger } \\
\text { movement }\end{array}$ & $\begin{array}{l}\text { 5. Write password (Assume 4-letter } \\
\text { word), K }\end{array}$ & $=5.87$ seconds \\
\hline 7. Click login button & 6. Finger move to login button, F & \\
\hline 8. Click most visited page & 7. Finger move to login button, $\mathrm{F}$ & \\
\hline 9. Click the files link feature & 8. Finger move to login button, F & \\
\hline 10. Look at phone & $\begin{array}{l}\text { 9. Click login button, B } \\
\text { 10. Look at phone, SMacro }\end{array}$ & \\
\hline
\end{tabular}

\section{4) Fourth Scenario}

Users opened the most visited element then checked the data information and clicked on the link if the user wanted to visit or view it (Table 9).

Table 9. $4^{\text {th }}$ scenario to get the total time

\begin{tabular}{lllll}
\hline \multicolumn{1}{c}{ Action Sequence } & & \multicolumn{1}{c}{ Operator Sequence } & Calculation of Total Time \\
\hline 1. & Initial Act & 1. & Start using mobile phone, I & $=\mathrm{I}+2 \mathrm{~F}+2 \mathrm{~B}+0.36$ \\
2. $\begin{array}{l}\text { Point to most visited feature by finger } \\
\text { movement }\end{array}$ & 2. & $\begin{array}{l}\text { Finger move to most visited } \\
\text { feature, F }\end{array}$ & $=1.18+(2 * 0.23)+$ \\
3. & Click most visited feature & 3. & Click most visited feature, B & $(2 * 0.1)+0.36$ \\
4. & Point to files feature by finger & 4. & Finger move to files feature, F & \\
& movement & 5. & Click the files feature, B & $=\mathbf{2 . 2}$ seconds \\
5. & Click the files feature & 6. & Look at phone, SMacro & \\
6. & Look at phone & & \\
\hline
\end{tabular}

This research also integrated the MOBICS with decision tree rules of J48. J48 decision tee rules computed the highest hit, which was captured from a user log data during the browsing and computes the size of each cloud storage if it is still available. Hence, J48 decision tree rules only provided the most appropriate cloud storage that still has storage space. This research conducted time comparison for intelligent pre-fetching as well. The time comparison was computed through two scenarios 
according to KLM. The first scenario used Dropbox of web browser to access data level 4 and second scenario used $\mathrm{J} 48$ decision tree rules to access data level 4 . Both scenarios were tested to access user data at level 3 to determine their speed access.

a) First Scenario to get the total time (Intelligent Pre-fetching)

In this scenario, the sequence was built to calculate the total action time without pre-fetching. The user needed to open the web browser then type the URL of website, such as: (www.dropbox.com 14letter word) then login as usual. The calculation is provided in Table 10.

Table 10. $1^{\text {st }}$ scenario to get the total time (Intelligent Pre-fetching)

\begin{tabular}{|c|c|c|}
\hline Action Sequence & Operator Sequence & $\begin{array}{c}\text { Calculation of Total } \\
\text { Time }\end{array}$ \\
\hline Initial act & Start using mobile phone, I & $=\mathrm{I}+7 \mathrm{~F}+7 \mathrm{~K}+4 \mathrm{~K}+2 \mathrm{~B}+$ \\
\hline $\begin{array}{l}\text { 2. Point to URL text box by finger } \\
\text { movement }\end{array}$ & $\begin{array}{l}\text { 2. Finger move to URL link box, F } \\
\text { 3. Write the URL link }\end{array}$ & 0.36 \\
\hline 3. Write the URL & (www.dropbox.com) & $=1.18$ \\
\hline 4. Point to username text box by & 4. Finger move to username text box, $\mathrm{F}$ & $+(7 * 0.23)+(18 * 0.28)$ \\
\hline $\begin{array}{l}\text { finger movement } \\
\text { 5. Write username }\end{array}$ & $\begin{array}{l}\text { 5. Write username (Assume 7-letter } \\
\text { word), K }\end{array}$ & $\begin{array}{l}+(7 * 0.28)+(4 * 0.28) \\
\quad+2 * 0.1+0.36\end{array}$ \\
\hline $\begin{array}{l}\text { 6. Point to password text box by } \\
\text { finger movement }\end{array}$ & $\begin{array}{l}\text { 6. Finger move to password text box, F } \\
\text { 7. Write password (Assume 4-letter }\end{array}$ & \\
\hline 7. Write password & word), K & $=11.70$ seconds \\
\hline $\begin{array}{l}\text { 8. Point to sign in button by finger } \\
\text { movement }\end{array}$ & $\begin{array}{l}\text { 8. Finger move to sign in button, } F \\
\text { 9. Click sign in button, B }\end{array}$ & \\
\hline Click the files link element & 10. Finger move to files link, $\mathrm{F}$ & \\
\hline $\begin{array}{l}\text { 10. Click the files link element (for } \\
\text { 2nd level) }\end{array}$ & $\begin{array}{l}\text { 11. Finger move to files link, } F \\
\text { 12. Finger move to files link, } F\end{array}$ & \\
\hline $\begin{array}{l}\text { 11. Click the files link element (for } \\
\text { 3rd level) }\end{array}$ & $\begin{array}{l}\text { 13. Finger move to files link, F } \\
\text { 14. Click the files link feature, B }\end{array}$ & \\
\hline $\begin{array}{l}\text { 12. Click the files link element (for } \\
\text { 4th level) } \\
\text { 13. Look at phone }\end{array}$ & 15. Look at phone $S_{\text {Macro }}$ & \\
\hline
\end{tabular}

b) Second Scenario to get the total time (Intelligent Pre-fetching)

A User opened the decision tree element then checked the data information and clicked on the link that the user wanted to visit or view (Table 11).

Table 11. $2^{\text {nd }}$ scenario to get the total time (Intelligent Pre-fetching)

\begin{tabular}{|c|c|c|}
\hline Action Sequence & Operator Sequence & $\begin{array}{c}\text { Calculation of Total } \\
\text { Time }\end{array}$ \\
\hline $\begin{array}{ll}\text { 1. } & \text { Initial act } \\
\text { 2. } & \text { Point to decision tree feature by } \\
\text { finger movement } \\
\text { 3. } \\
\text { 4. } \text { Plick decision tree feature } \\
\text { movement } \\
\text { 5. Click the files feature } \\
\text { 6. Look at phone }\end{array}$ & $\begin{array}{ll}\text { 1. } & \text { Start using mobile phone, I } \\
\text { 2. } & \text { Finger move to decision tree } \\
& \text { feature, F } \\
\text { 3. } & \text { Click decision tree feature, B } \\
\text { 4. } & \text { Finger move to files feature, F } \\
\text { 5. } & \text { Click the files feature, B } \\
\text { 6. } & \text { Look at phone, SMacro }\end{array}$ & $\begin{array}{l}=\mathrm{I}+2 \mathrm{~F}+2 \mathrm{~B}+0.36 \\
=1.18+(2 * 0.23)+(2 * 0.1)+ \\
0.36 \\
=\mathbf{2 . 2} \text { seconds }\end{array}$ \\
\hline
\end{tabular}

The results for the proposed work of the MOBICS have increased the speed in accessing data utilizing the mobile-based for the MCS. Moreover, an access time comparison of the four scenarios are presented to explain the performance time difference for local pre-fetching while the two scenarios are presented to explain the performance of intelligent pre-fetching using $\mathrm{J} 48$ decision tree rules as illustrated in Fig. 6.

The total time using advanced KLM is plotted in Fig. 6, approximately 11.47 seconds, was needed for local pre-fetching in scenario 1 which used the normal browsing via mobile phone. It was different when using the Mobile Pre-fetching implemented in a cloud storage environment, as it required only 2.2 seconds for the user to access the data, which was faster compared with the other. Furthermore, the intelligent pre-fetching only needed 2.2 seconds to access the data compared to the normal browser in scenario 1. In this paper shows the contribution in improving the efficiency and effectiveness of 
users' interaction for the proposed MOBICS with the traditional MCS. It showed time reduction of interaction up to $19.28 \%$ (2.2 seconds in comparison to 11.47 seconds) for the local pre-fetching and $18.80 \%$ ( 2.2 seconds in comparison to 11.70 seconds) for the intelligent pre-fetching.

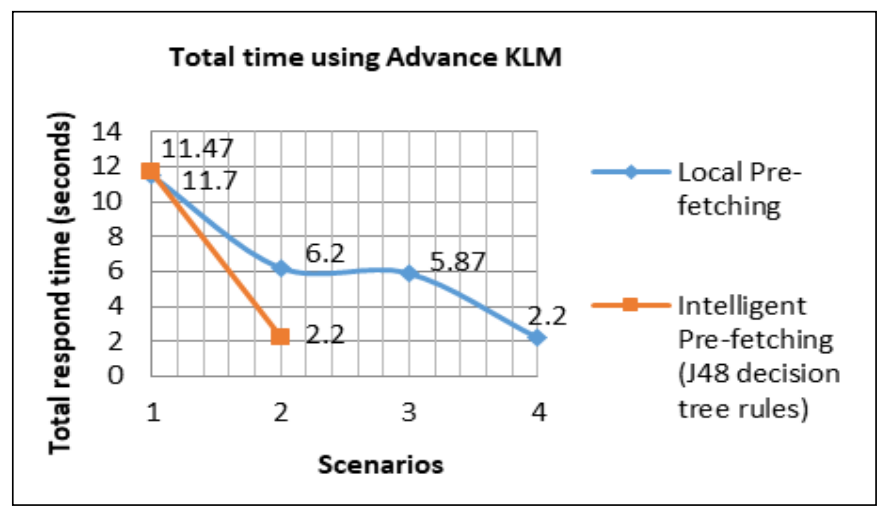

Fig. 6.Local and Intelligent Pre-fetching performance of access time comparison using KLM

\section{Conclusion}

This paper has enhanced the performance of Web pre-fetching for mobile cloud storage applications by proposing the MOBICS scheme. This scheme comprises of two schemes consisting of firstly, a scheme to analyse and determine the best ML technique in predicting pre-fetched objects; and secondly, a scheme to implement the best ML technique (J48 Decision Tree rules) into MCS environment to speed up and increase the scalability in accessing the data files on multiple cloud storage services. It can be seen that the proposed scheme for the intelligent technique was faster than the traditional Dropbox Mobile application access. MOBICS was more rapidly than usual browsing performance without pre-fetching. This result proves by most of the respondents with 95.65\% (66 from 69 respondents) agreeing that MOBICS system was extremely practical and has enhanced the rate in accessing and storing MCS. The correspondence between efficiency, as indicated by task completion time, and effectiveness, as indicated by quality of solution, was negligible. Effectiveness, which is the accuracy and completeness with users achieve certain tasks. An indicator of effectiveness is quality of solution by measure of the outcome of user's interaction with the system based on questionnaire. Efficiency, which is the relation between the accuracy and completeness with users achieve certain task and resources expended in achieving them. In this research, use task completion time as the indicator of efficiency. In addition, users' usability measured based on SUS which provides a global view of subjective assessments of usability.

The statistical test (chi-square test) also proved that background of respondents did not affect the respondents' ranking feedback on MOBICS implementation, hence MOBICS awareness from Hawthorne Effect, which means the evaluation was valid as depicted in Tables 4 and 5. A statistical test was evaluated based on $\mathrm{Chi}^{2}$ statistic and $\mathrm{I}^{2}$ statistic. The value of $\mathrm{P}>0.05$ of all aspects of profile background showed that gender, race, age and education level did not influence the ranking of MOBICS feedback. Moreover, the result of $\mathrm{I}^{2}$ was less than $40 \%$ might not be important for ranking of MOBICS feedback. It concluded that the proposed MOBICS had less Hawthorne effect because the majority of the results get effectively to use it and not for the reason being observed.

\section{Acknowledgment}

This research is supported by Ministry of Higher Education Malaysia (MOHE), Ministry of Science, Technology and Innovation Malaysia (MOSTI) and Universiti Teknologi Malaysia (UTM). This paper is financially supported by E-Science Fund, R.J130000.7928.4S117, PRGS Grant, R.J130000.7828.4L680, GUP Tier 1 UTM, Q.J130000.2528.13H48, FRGS Grant, R.J130000.7828.4F634 and IDG Grant, R.J130000.7728.4J170.The authors would like to express their deepest gratitude to the Centre for Information and Communication Technology (CICT), for their support in providing the data sets to ensure the success of this research, as well as a Soft Computing Research Group (SCRG) for their continuous support and fondness in making this research possible. 


\section{References}

[1] C. R. Harrell, B. Gladwin, and M. P. Hoag, "Mitigating The 'Hawthorne Effect' In Simulation Studies Charles,” Proc. Winter Simul. Conf., no. 2004, pp. 2722-2729, 2013.

[2] R. Macefield, "Usability Studies and the Hawthorne Effect," J. usability Stud., vol. 2, no. 3, pp. 145-154, 2007.

[3] J. McCambridge, J. Witton, and D. R. Elbourne, "Systematic review of the Hawthorne effect: new concepts are needed to study research participation effects.," J. Clin. Epidemiol., vol. 67, no. 3, pp. 26777, Mar. 2014.

[4] M. Chiesa and S. Hobbs, "Making sense of social research: How useful is the Hawthorne Effect?," Eur. J. Soc. Psychol., vol. 38, no. 1, pp. 67-74, 2008.

[5] M. del P. Villamil G and C. J. Urango M, "Pocket Caching: A Strategy of Prefetching Cache Based on Multi-objective Optimization for Mobile Cloud Computing," Int. J. Comput. Theory Eng., vol. 8, no. 2, pp. 94-101, 2016.

[6] D. Anu and A. P. A, "Negotiate Emulation Data Prefetching in Diffuse File Conformity for Cloud Enumerate," Int. J. Res. Emerg. Sci. Technol., no. 1, pp. 10-14, 2016.

[7] X. Wang and M. Chen, "PreFeed : Cloud-Based Content Prefetching of Feed Subscriptions for Mobile Users," IEEE Syst. J., vol. 8, no. 1, pp. 202-207, 2014.

[8] N. Sharma and S. K. Dubey, "Semantic based Web Prefetching using Decision Tree Induction," 2014 5th Int. Conf. - Conflu. Next Gener. Inf. Technol. Summit, pp. 132-137, Sep. 2014.

[9] J. Brooke and others, "SUS-A quick and dirty usability scale," Usability Eval. Ind., vol. 189, no. 194, pp. 4-7, 1996.

[10] L. O. Colombo-Mendoza, G. Alor-Hernández, A. Rodr'liguez-González, and R. Valencia-Garc'lia, "MobiCloUP!: a PaaS for cloud services-based mobile applications," Autom. Softw. Eng., vol. 21, no. 3, pp. 391-437, 2014.

[11] P. Lilly, “Top 20 cloud storage services," 2013. [Online]. Available: http://www.techadvisor.co.uk/feature/storage/top-20-cloud-storage-services-3421715/. [Accessed: 16Feb-2014].

[12] S. Mitroff, "OneDrive, Dropbox, Google Drive and Box: Which cloud storage service is right for you?," 2016. [Online]. Available: https://www.cnet.com/how-to/onedrive-dropbox-google-drive-and-boxwhich-cloud-storage-service-is-right-for-you/. [Accessed: 10-Nov-2017].

[13] M. Casserly, “The 14 best cloud storage services 2017," 2017. [Online]. Available: http://www.techadvisor.co.uk/test-centre/internet/best-cloud-storage-services-2017-3614269/. [Accessed: 10-Nov-2017].

[14] J. Higgins and S. G. Thompson, "Quantifying heterogeneity in a meta-analysis," Stat. Med., vol. 21, no. 11, pp. 1539-1558, 2002.

[15] J. P. T. Higgins, S. G. Thompson, J. J. Deeks, and D. G. Altman, "Measuring inconsistency in metaanalyses," BMJ Br. Med. J., vol. 327, no. 7414, p. 557, 2003.

[16] T. B. Huedo-Medina, J. Sánchez-Meca, F. Mar'lin-Mart’linez, and J. Botella, “Assessing heterogeneity in meta-analysis: Q statistic or I\$^2\$ index?,” Psychol. Methods, vol. 11, no. 2, p. 193, 2006.

[17] P. Holleis, F. Otto, H. Hussmann, and A. Schmidt, "Keystroke-level model for advanced mobile phone interaction," in Proceedings of the SIGCHI Conference on Human Factors in Computing Systems, 2007, pp. 1505-1514.

[18] P. Holleis, M. Scherr, and G. Broll, "A revised mobile KLM for interaction with multiple NFC-tags," Human-Computer Interact. 2011, pp. 204-221, 2011.

[19] Y. Jimenez and P. Morreale, "Design and evaluation of a predictive model for smartphone selection," in International Conference of Design, User Experience, and Usability, 2013, pp. 376-384.

[20] N. Karousos, C. Katsanos, N. Tselios, and M. Xenos, "Effortless tool-based evaluation of web form filling tasks using keystroke level model and fitts law," in CHI'13 Extended Abstracts on Human Factors in Computing Systems, 2013, pp. 1851-1856. 